\title{
Learning as Intellectual Empowerment
}

\author{
Nathalie Bulle ${ }^{1, *}$ \\ ${ }^{1}$ Dept. of Sociology (Groupe d'Etude des Méthodes de l'Analyse Sociologique de la \\ Sorbonne, GEMASS), National Center of Scientific Research (CNRS), Paris, France \\ *Correspondence: E-mail: nathalie.bulle@wanadoo.fr
}

Received: June 21, 2013 Accepted: August 2, 2013 Published: August 7, 2013

doi:10.5296/ije.v5i3.3884 URL: http://dx.doi.org/10.5296/ije.v5i3.3884

\begin{abstract}
Now more than ever, modern teaching has to find the secret of the cognitive economy that will permit the reconciliation of the ever-increasing mass of knowledge with the limited cognitive abilities of individuals, and of the training needs of highly specialized experts with requirements for high level, general understanding. We put forward elements towards a solution, starting from the question of what the notion of a "well-made head" might signify today. The hypothesis developed is that training the mind in any given field involves an understanding of the concepts and key ideas that form the basic structure of that field.
\end{abstract}

Keywords: intellectual development; developmental psychology; epistemology; discipline structure; physics teaching 


\section{Introduction}

According to Philip Phenix, an American philosopher and mathematician, the modern-day crisis in education can be explained by the extensive amount of knowledge that has to be mastered these days in comparison to the low cognitive abilities of individuals. In 1956 he wrote that this could be the major problem of contemporary education. This crisis in education is exacerbated by a dilemma: the demand for both good technical skills and liberal education that is, in the philosophical sense, committed to a deep and vast understanding of the natural and human world. The training of highly specialized experts is an economic imperative. But the blinkered view and fragmentation of knowledge which come as a result of specialization threaten to "destroy the delicate balance of civilized order". So this is the equation posed by Phenix that needs to be solved by modern education: the increasing mass of knowledge in the face of the intrinsic weakness of man's cognitive abilities, and the need for highly specialized experts in contrast with the need for a general overview and understanding. The solution to this equation calls upon the still somewhat mysterious concept of the "well-made head", of the teaching means of cognitive economy, and even the intelligence of the things it allows.

First of all, we will remind Montaigne's conceptions regarding the "well-made head" and uphold that they fall within the framework of meaningful learning - to borrow Ausubel (1963)'s terms - needing to be developed in the light of modern epistemology and psychology. In this regard, three major currents will be distinguished: classical empiricism, pragmatism, and cognitive rationalism. We will retain the third, which alone allows us to pose the problem of the nature of knowledge and, in this respect, that of the cognitive economy we seek. Using physics as an example, we will then evoke ways of developing in students a lifelong capacity to understand natural phenomena. It follows from this analysis that a teacher's firm mastery of the subject is a prerequisite to an educational method that aims for the student's understanding of the rational foundations of a discipline.

\section{The Well-Made Head Concept}

Today's development of knowledge does not necessary lead to a redefinition of the fundamental teaching missions of the school. Have we not been asking, since the 16th century at least, for well-made heads? Montaigne's view on this subject was that it was a question of training able, rather than erudite, people, guides or "masters" with a well-made rather than a well-filled head. He required both these qualities, but considered character and understanding more important than science itself.(Note 1) Looked at closely, it is a straightforward order of priority that does not put into opposition the terms he set out. Let us put aside the question of morals or ethics. For education purposes, it is primarily judgment that schools put most effort into, giving it depth, intensity, amplitude and, consequently, autonomy. There is therefore no need to invoke the increasing amount of knowledge produced nowadays to conclude that cognitive economy is what is expected from learning. That is what represents the timeless goal of any intellectual education. 
The relationship established by Montaigne between the teacher's well-made head and the future ability of the student is of paramount importance. It reveals a relationship which is not merely based on knowledge, but more essentially on the intelligence of things. If this intelligence is weak, if the teacher keeps going over knowledge that is always specific, or even purely informational, he/she can only mechanically reproduce in the student this sterile knowledge, which is often termed as encyclopedic, generally without clearly distinguishing "information" from "knowledge". Montaigne's view is supported therefore, from the very first lines of On the education of children, by a principle of mediation in the sense that the teacher aims to foster the student's understanding capacity by developing his/her intelligence of things. This is a far cry from Emile's teacher, who is not interested in science but in "the appropriate instrument for acquiring it” (Rousseau [1762] 1969: 207), because this teacher basically aims to train the mind how to acquire "a science" to which he attaches no cognitive value. This aim is also present in the flawed "learning to learn" formula, which assigns a too modest objective to formal education since it appears to only be a question of developing storing potential. Conversely, right from the outset Montaigne points to a logic of mediation that aims to increase students' capacity for judgment or, in other words, the intelligence of things.

So what is this intelligence of things, and what does it require from teachers? This intelligence of things, regardless of the things in question - and we know that education has seen its objects of predilection change over the ages - raises hypotheses in theory of knowledge and psychology that will probably never have any value as definitive truths. We know that, to develop this further, Plato relied on preparation for dialectics; the Carolingian Renaissance relied on grammar, which gave access to the Holy Scriptures; and Scholasticism relied on logical argumentation. Montaigne himself was quietly critical of this Scholastic logic, which nevertheless aimed for a general training of intelligence. But Scholasticism, during the Renaissance, no longer seemed able to offer the means for this cognitive economy, this understanding of the world that appears to be at the root of the philosophical idea of liberal education. In Pédagogie française, Paul Lapie (1920) explains there is no doubt that students in the Middle Ages sharpened their judgment: they had to look for the "pros" and "cons" of any argument and were required to rigorously structure their reasoning; however, in discussions of School, the last word was never accorded to reason, but to the book. The mind, writes Lapie, "bows down before authority”. We claim to teach the art of thinking, but we only create intellectual routines or "syllogism machines". Scholastic teaching "overloads the memory to the point of stifling judgment ... it wears down the mind in vain discussions instead of enriching it through the observation of realities" (Lapie, 1920: 2). Science in the Middle Ages, in a proto-scientific state, was based on what authorized authors had said about things. Reason had taken a step forward, it had turned to the study of its own mechanisms to develop its understanding of the world, but it remained trapped in established frameworks and systems of thought without returning to reality.

Perhaps Montaigne also had in mind, as Durkheim (1938, Liv. II chap. III) explains, Erasmus ([1512] 1904: 522 e-523f), who was too attached to beautiful language, or Rabelais, who was too attached to science itself. In this respect, Erasmus called for very learned teachers but 
this erudition prefigured a substantial education: teachers had to be able to offer their students the best literature. Nevertheless, in the final analysis, we have to return Montaigne to his place and retain not so much the pedagogical conceptions that must evolve with progress made in epistemology and psychology, but the more general aim of pedagogy contained in the idea of a well-made head, which we translate as the intelligence of things. Let us hear Montaigne recommending that "learning" rests on this understanding upon which intellectual development appears to implicitly depend: "Let him be asked" - writes Montaigne ([1572] 1957: 110) - "not merely of the words of his lesson, but of its sense and substance; and let him judge the profit he has made by the testimony, not of his memory, but of his life". We can see that "meaning and substance" do not call upon the formation of a "bucket mind", a term used by Karl Popper (1972) when referring to classical empiricist conceptions. In other words, they do not call upon a mind that collects and reassembles information or ideas, but a mind that maintains a reflexive and comprehensive relationship with knowledge.

\section{The Nature of Knowledge in Modern Thought}

To take this further and study what liberal educational thinking might represent today, we have to question the nature of knowledge as the intelligence of things, in order to possibly derive from this a few fundamental principles for teachers and pupils education. Within this perspective, we propose to distinguish three major currents of thought that underpin modern psychology and epistemology: classical empiricism, linked to association psychology; pragmatism, linked to the functionalist or adaptive premises of psychology, and what we may call cognitive rationalism, linked to historical-cultural psychology.

The first and second currents are naturalisms - i.e. based on the assumption of continuous development from basic mental functions to higher mental functions. The second and the third currents are constructivisms. The initial premise of constructivism is that thought preforms the data of experience to produce knowledge, whereas for associationists thought develops by establishing links between perceived pieces of information that make up simple ideas and these last, by association, make up complex ideas.

Associationist psychology, modernized by behaviorism, comes into play when discussing the transmission of factual knowledge that is either purely mechanical, or induced following a logic that relies on the power of things - i.e. the impact of external relationships in the environment on the formation of internal relationships in the mind. This logic of development assumes a conception of the knowing subject that is both subjective and passive. For behaviorism, which has had an influence on contemporary conceptions in teaching competency-based approaches in particular(Note 2) - that must not be underestimated(Note 3), the intelligence of things cannot be a relevant notion. Such an intelligence of things is linked in an irreducible way to the activity of consciousness and such an activity does not interest upholders of behaviorism. Due to a field of study anchored in animal psychology, learning, for the behaviorist, is essentially aimed at the development of behavioral competences based on practical experience - i.e. close to real-life situations(Note 4) - and on specific teachings applied to isolated aspects of each activity. (Note 5) 
The other two major currents of modern psychology and epistemology lead us to distinguish two forms of constructivism. Constructivism is the perspective commonly shared today, as mentioned above - and that we designate commonsense constructivism - according to which reality is knowable only on the basis of structures that a subject (individual or collective) imposes on knowledge.

Detaching itself from this is a radical constructivism according to which knowledge is essentially adaptive: to the extent that the subject contributes to the knowledge, the consequence that is deduced, and drawn from an essentially inductive and experiential conception of the construction of concepts, is that there is no "objective" knowledge because "concepts can only be constructed in the empirical world of an individual" (Glasersfeld 2001: 202). This logic of development assumes, this time, a conception of the knowing subject that is both subjective and active. Such an adaptive approach is particularly defended by authors whose constructivism is rooted in the psychology of Piaget. From this follows the idea that concepts that are the subject of teaching cannot be even approached in an explicit way, but must be constructed in the minds of individuals based on their own activity. The very meaning of concepts is associated with the particular situations in which they are implicated: it calls upon "all the schemata used by the subject in these situations" (Vergnaud 1990:145). The teacher cannot transmit ready-made "action schemata" but, in this context, can only guide the learning process. Note that the teacher will have been trained in the same way, by being placed in situations likely to enable him to develop suitable action schemata.

Radical constructivism justifies educational objectives that come to be defined in terms of behavior - of competencies conceived of as capacities to appropriately intervene in given situations, or even as behavioral capabilities. In such a framework, knowledge is supposed to have an active role only when it is an integral part of "action schemata". Consequently, a behaviorist orientation that was thought to have been excluded finds itself reintroduced. This "radicalized" constructivism is incapable of accounting for the formation of an "intelligence of things", that is to say, decontextualized thought applied to the understanding of reality and independent of the action exerted on it at any given time - i.e. scientific or conceptual understanding. It is significant in this regard that radical constructivism does not confer any reality on the third world Popper (1972) places next to the physical world and the world of subjectivity, a world of human works and theories, and the only one likely to create a public space for knowledge.

The third major current that we mentioned, identified as cognitive rationalism, is linked to advances of epistemology that have accompanied the development of modern physics, as represented in the various epistemologies attached to the names of Emile Meyerson, Filmer Northrop, Henry Margenau, Gaston Bachelard, Karl Popper, etc. These epistemological views group around what Cunningham and Fitzgerald (1996) identified as a hypothetico-deductivist cluster. They oppose to ancient essentialist or realist trends acknowledging a correspondence model of truth - by their conception of knowledge as being only in correlation with the phenomenal world. But they oppose also to experiential theories of knowledge since they conceive theoretical hypotheses and relative autonomous conceptual systems they are in relation with as forming public pieces of knowledge which give meaning 
to the data of experience. According to this cluster of epistemological views, scientific understanding is not directly supported by concrete practices and objects. Consequently, experience as such is not conceived as the inroad to all knowledge. The latter have only an indirect relationship with intellectual constructs that are used to decipher the world: it serves as illustration, not anchor.

These currents, which are consistent with the historical-cultural psychology of Lev Vygotsky ([1934] 1986), shed light on the nature of the intelligence of things that is the object of our inquiry, which, far from stopping at simple knowledge, without structure, depth or spirit, is strongly attached to understanding, and consequently to capacities for critical thinking.

\section{The Structure of Knowledge and Human Understanding}

Here we return, in a very general sense, to Phenix's point of view, which we mentioned in the introduction. Knowledge, explains Phenix, is not an accumulation of independent items of information: individual items are interconnected in systems of ideas. Among these ideas, families of resemblance can be discerned and these offer a key to the process of cognitive economy, which is the object of intellectual education. It is indeed possible to "know physics", not by becoming familiar with all the specific facts and theories usually included in this domain, but by understanding the common traits that link individual items to this domain. Cognitive economy rests on the ability of human intelligence to form concepts that simplify experience by the development of general ideas. However, the formation of concepts applies not only to the classification of perceptual objects, but also to the organization of the facts and theories that constitute knowledge - which justifies commonsense constructivism. Phenix writes that we recognize the economy permitted by the use of a concept such as "dog" instead of individual enumerations. We do not see as clearly the need for concepts that summarize the essential characteristics of a class of ideas in a field of knowledge such as physics or psychology. Yet these are fundamental ideas that allow real access to an entire domain of knowledge. These "key ideas" represent a "map" from which the overall outline of a topic can be apprehended and the characteristics of individual items of knowledge can be, for the first time, correctly interpreted. It is to be feared in this regard that certain individual propositions in mathematics might never be truly understood unless certain key ideas from mathematics as a whole are themselves understood.

In a text that is often quoted because it made history in the United States in the 1960's during the controversy about the role disciplines play in the curriculum (Davis 1963), Phenix (1962) points to the idea, prevalent in education at the time, that disciplines have something of the nature of pure knowledge, which is interesting for academic studies and research, but not directly related to the goals of education. The curriculum was then supposed to bring into play situations drawn from real life, problems, projects, etc. as the primary teaching content, with disciplinary knowledge only serving as secondary material to be used according to the needs of the educational process. Phenix defends the opposite view that disciplines, in bringing together a large set of elements of cognition in a common structure of ideas, simplify understanding while constructing complex cognitive structures that bring ideas 
together in coherent sets - there, concepts are not apprehended in isolation but through their relationships and interconnections.

Our hypothesis, which follows Phenix's reasoning, is that the intelligence of things, in a given domain, has something of the nature of the understanding of these key concepts. And this understanding, which must be a fundamental objective in schools, deeply involves teachers' education. The latter must above all master the rational foundations of their discipline and build their teaching in the light of these essential principles. (Note 6) This does not mean that the key concepts should be taught explicitly and directly, at least not to beginners, states Phenix. This means that knowledge must be selected and used with a view to illustrating the basic concepts of the domain, concepts that differ in nature from one domain to another(Note 7). Let us remember that the notion of illustration is fundamental for understanding that which opposes learning theories that aim for the development of action schemata with those that aim for elementary rational understanding of a field of knowledge. For the second type of learning theories, experience does not serve the actual construction of knowledge of the subject; it reveals the possible correspondent relationships between the concepts and key relationships that constitute the domain in question, and reality.

This elementary rational understanding constitutes the very motivation for future individual developments, both professional and personal. Conversely, it may be argued that its absence is what lies behind mechanical teaching methods, which are not only scarcely effective and without developmental value, but also sources of boredom and failure.

\section{The Teaching of Physics}

The remarks of an American university professor of physics, Henry Crew, set out in an article published in 1900, illustrate these views in a domain that is particularly interesting because it has no doubt yet to experience its golden age in education, even though it is of major concern in contemporary education: physics. "What, ought we to do", writes this professor, "that we are not now doing, in order that the mature man may look back to his course in physics as a source of inspiration, as work in which his judgment was trained, and work in which he discovered good method ?” (Crew 1900: 521). And the professor proposes that physics should be presented in a more elementary way: "Not necessarily easier, not necessarily more difficult; but more elementary. Not necessarily more profound; certainly not more superficial; but more simple”, he writes. In this regard, we must not confuse simple with concrete. Such an assimilation goes back to associationism in psychology. Since Kant we know at least that no apprehension of the world by human reason is exempt from a share of abstraction that constitutes not what renders it more complex, but what simplifies it. Elementarization, which is dear to Condorcet ([1791-1792] 1989), is something of the nature of an analytical reduction of knowledge and not a false simplicity associated with a direct apprehension of phenomena. According to the physicist, it involves four conditions. Firstly, the unity of knowledge - as opposed to its breakdown into procedures and problem situations. Secondly, and on this basis, it is founded on the development of key concepts; thirdly, it requires a progressive logical presentation of the discipline and finally, fourthly, it assumes strong mastery of the subject by 
the teacher. As a model of teaching success, Crew uses that of the teaching of the classics at the time, which presents these qualities: it is based, he explains, on a progressive construction that begins with declensions and the practice of simple sentences; it is provided by a teacher who deeply believes in the unity of his/her subject: for the teacher, Latin literature is one subject. And he/she can boast of the central position of this discipline in the curriculum from the moment it forms men who "can do more than understand illusions to Grecian mythology or explain classical references - that is to say, men who can produce literature" (Crew 1900:520). The effectiveness of a physics course should be judged on the same standards: the development of clear, independent thinking that underpins the ability to produce original scientific results. However, the popularization of learned knowledge by schools, involving vague notions and approximate definitions, and a quantity of properties that are accepted without critical questioning, cannot support such a development. The latter requires an understanding of the fundamental principles involved - even if such principles may change with the advances of science: one cannot "find out anything of value concerning the nature of light without previously learning something of the nature of wave motion" (Crew 1900: 523). Developing teaching based on problems that are complex from the outset (as they are in everyday life) when the students have not yet mastered the basic concepts of the discipline, in reality makes the discipline appear "very complicated" to the students. Such teaching does not lead to cognitive development because the students cannot understand the links the concepts have between one another and with fundamental principles (Vygotsky [1934] 1982). Only a progressive and rational development of the subject offers students a means of fundamental understanding, enabling them to reason independently of the specific contexts of learning. On this subject, Crew claims it is not enough that the teacher believes in the conservation of matter and energy, or in a system's trend toward a minimum of potential energy. It is not even enough that he/she states these principles when considering the subject of mechanics. The teacher must demonstrate, adopt and continually use four or five of these experimental general principles that help to explain a large part of physics, because they constitute its foundations(Note 8) "The subject of physics will become simple and unified only when these principles are in daily use throughout the study of the phenomena of hydrostatics, heat, capillarity, electricity, and magnetism” (Crew 1900: 523). Each group of new phenomena taught must then simply serve as an illustration of these few general principles.

\section{Conclusion}

In conclusion, the pedagogic condition for an elementary teaching of knowledge that is capable of supporting the intelligence of things that make up its field - the development of the well-made heads so dear to Montaigne - is the teacher's strong mastery of his/her domain. Such a condition does not weaken the very idea of education, quite the contrary. The latter has found itself burdened by assumptions inspired by adaptive psychologies, which claim that methods based on individual and group experiences are what serve the development of cognitive capacities. On the contrary, the educational method defended here involves the teaching of elementary ideas that are the building blocks of a discipline. It requires, on the 
part of the teacher, the ability to develop such teaching in a consistent, structured and progressive way, as well as the ability to link phenomena up with the fundamental principles that shed light on them. The teacher must not hide behind any textbook or, let us add, any digital educational tool or anything else, but rise above these and teach his/her subject logically from a plan he has adopted or invented. If the teacher cannot rise above the scope of a textbook, Crew states, there is no hope of him/her making physics simple, or using physics to develop scientific minds.

"In my own experience”, writes the physics professor, "I recall many chapters in physics the presentation of which I omitted on account of their complexity as I then thought. Among these subjects were elasticity, diffraction of light, capillarity. But never a year has passed that something of this kind has not cleared itself up, by more study on my part, so that now I am able to present it to my students in a vastly simpler and clearer way than ever before. The complexity which I had assigned to the subject proved later to be nothing but my own uncertain grasp of the subject” (Crew 1900: 525).

\section{References}

Aharoni, R. (2005). What I learned in elementary school. American Educator, 29(3). Retrieved from http://www.aft.org/newspubs/periodicals/ae/fall2005/aharoni.cfm

Ainsworth, D. (1977). Examining the Basis for Competency-based Education. The Journal of Higher Education, 48(3), 321-332. Retrieved from http://www.jstor.org/stable/1978684

Ausubel, D.P. (1963). The Psychology of Meaningful Verbal Learning. New York: Grune \& Stratton.

Chevrier, M. (Ed.). (2010). Par-delà l'école-machine. Critiques humanistes et modernes de la réforme pédagogique au Québec. Québec: Multimondes.

Condorcet, N. de [1791-1792] (1989). Cinq mémoires sur l'instruction publique. Paris: Edilig.

Crew, H. (1900). What Can Be Done to Make the Study of Physics a Better "Training for Power?". The School Review, 8(9), 520-527. Retrieved from http://archive.org/details/jstor-1074985

Cunningham, James \& Fitzgerald, Jill. (1996). Epistemology and reading. Reading Research Quarterly, 31(1), 36-60. http://dx.doi.org/10.1598/RRQ.31.1.3

Davis, O. L. (1963). Organized Knowledge Influencing Curriculum Decisions. Review of Educational Research, 33(3), 245-253. http://dx.doi.org/10.3102/00346543033003245

Durkheim, E. [1938] (1990). L'évolution pédagogique en France. Paris: PUF.

Erasmus D. [1512] (1904). De Ratione Studii et instituendi pueros commentarii. In Harrison,W.W. Desiderius Erasmus Concerning the Aim and Method of Education. London: Cambridge University Press. 
Lapie, P. (1920). Pédagogie française. Paris: Alcan.

Ma, L. (2010). Knowing and teaching elementary mathematics: Teachers' understanding of fundamental mathematics in China and the United States. London: Taylor \& Francis.

MacDonald-Ross, M. (1973). Behavioural Objectives - A Critical Review. Instructional Science, 2(1), 1-52. http://dx.doi.org/10.1007/BF00143061

Montaigne, M. de [1572] (1957). The Complete Essays of Montaigne. Stanford: Stanford University Press.

Montaigne, M.de [1572] (1978). Les Essais. Paris: PUF.

Perrenoud, P. (1997). Construire des compétences dès l'école. Issy-les-Moulineaux: ESF editeur.

Phenix, P. (1962). The Uses of the Disciplines as Curriculum Content. Educational Forum, 26, 273-280.

Planche, A. (2012). L'imposture scolaire. La destruction organisée de notre système éducatif par la doctrine des (in)compétences. Bordeaux: PU Bordeaux.

Popper, K. (1972). Objective Knowledge: An Evolutionary Approach. Oxford: Oxford University Press.

Rousseau, J.J. [1762] (1969). Emile ou de l'éducation. Paris: Gallimard.

Skinner F. [1948] (1962). Walden Two. New York, NY: Macmillan.

Thorndike, E. (1913). Educational psychology: The psychology of learning. New York, NY: Teachers College Press.

Vergnaud, G. (1990). La théorie des champs conceptuels. Recherches en Didactique des Mathématiques, 10(2-3), 133-170.

Von Glasersfeld, E. (2001). Constructivisme radical et enseignement. Canadian Journal of Science, Mathematics and Technology Education, 1(2), 211-222. http://dx.doi.org/10.1080/14926150109556462

Vosniadou, S. (2007). The cognitive-situative divide and the problem of conceptual change. Educational Psychologist, 42(1), 55-66.

Vygotsky, L.S. [1934] (1986). Thought and language. Cambridge, MA: MIT Press. 


\section{Notes}

Note 1. "Since I would rather make him an able man than a learned man, I would also urge that care be taken to choose a guide with a well-made rather than well-filled head; that both these qualities should be required of him, but more particularly character and understanding than learning” Montaigne ([1572] 1957: 110).

Note 2. These approaches dominate contemporary changes in education being made in OECD countries. In existence for a longer time in Anglo-Saxon countries, they are developing in French-speaking countries on the basis of the redefinition of teaching objectives in behavioral terms - cf. the work of Marc Chevrier (Ed.) (2010) and Alain Planche (2012) for examples from Quebec and France. According to some of their instigators, schools have to abandon the theoretical teaching objectives of disciplines by grounding educational programs in social practices that are incorporated into concrete contexts, such as negotiating a contract, facing up to a family crisis, trying to balance a budget or forming a personal opinion about a controversial issue, etc. Cf. Perrenoud (1997).

Note 3. Cf. some major analyses published on this subject in the 1970s: Ainsworth D. (1977); MacDonald-Ross, M. (1973).

Note 4. Cf. for example the educational conceptions of Skinner ([1948] 1962: 119-120).

Note 5. This is what, in particular, ensues from the connectionist conceptions of a precursor of behaviorism such as Edward Thorndike (1913).

Note 6. This is the fundamental teaching of the interesting comparison carried out by Liping Ma (2010) of methods of teaching mathematics in primary schools in China and the USA. Cf. also on this subject, comments by the mathematician Ran Aharoni (2005) on his teaching experience.

These conceptions seem to us to be in agreement with current theories of conceptual change (Vosnadiou 2007).

Note 7. In this regard, according to Phenix, science is characterized by the abstractions that it creates, that is to say, perspectives or models of measurable relationships between things; mathematics represents an axiomatic science that is entirely dependent on selected rules of deduction; history is distinguished as an interpretative science by the selection it carries out among events; whereas art consists of the study of concrete individual sets, etc.

Note 8. According to Crew, the central principles in question were, in 1900, the conservation of matter; the conservation of energy; the tendency of a system's potential energy to become minimal; Newton's laws of motion; the general principles of wave motion.

\section{Copyright Disclaimer}

Copyright reserved by the author(s).

This article is an open-access article distributed under the terms and conditions of the Creative Commons Attribution license (http://creativecommons.org/licenses/by/3.0/). 